\title{
Toezicht en handhaving bij het verplicht bod in Nederland
}

\author{
J. Schipper \& H. Koster
}

\section{$1 \quad$ Inleiding}

Door de Richtlijn 2004/25/EG van 21 april 2004 betreffende het openbaar overnamebod (hierna: Overnamerichtlijn) is er een EU-regeling voor het verplicht bod geïntroduceerd. In Nederland is een (rechts)persoon die overwegende zeggenschap verkrijgt in een beursgenoteerde vennootschap vanaf 28 oktober 2007 verplicht om een openbaar bod uit te brengen op alle overige uitstaande aandelen en certificaten die met medewerking van de vennootschap zijn uitgegeven. ${ }^{1}$ De verplicht-bodregeling beoogt onder meer aandeelhouders te beschermen door een 'billijke' uitweg te bieden indien de zeggenschap in de vennootschap wijzigt. ${ }^{2}$ Naast de bescherming van minderheidsaandeelhouders wordt aangevoerd dat de verplicht-bodregeling bijdraagt aan de efficiëntie van de kapitaalmarkt. ${ }^{3}$

In dit artikel onderzoeken wij hoe het toezicht op en de handhaving van de verplicht-bodregeling is vormgegeven in Nederland en in enkele andere landen. Daarna zullen wij de vraag beantwoorden of er argumenten zijn om het toezicht op en de handhaving van de verplicht-bodregeling in Nederland te herzien. $\mathrm{Na}$ kort aandacht voor de relevante aspecten van de Overnamerichtlijn komen het toezicht op en de handhaving van de biedplicht in Nederland in paragraaf 2 aan bod. In paragraaf 3 wordt gekeken naar de toezichtspraktijk in enkele andere EUlidstaten. In paragraaf 4 beantwoorden wij vervolgens de vraag of er argumenten zijn om het toezicht op en de handhaving van de verplicht-bodregeling in Nederland te herzien. Wij sluiten in paragraaf 5 af met enkele conclusies.

\section{Toezicht en handhaving bij het verplicht bod}

\subsection{Toezicht en handhaving bij het verplicht bod: Overnamerichtlijn}

De Overnamerichtlijn wijdt enkele bepalingen aan het toezicht en de handhaving van de richtlijn. Zo blijkt uit overweging 5 van de Overnamerichtlijn en uit art. 4 lid 1 van de Overnamerichtlijn dat de lidstaten een of meer autoriteiten moeten aanwijzen die belast zijn met het toezicht op een bod dat onder de krachtens de

1 Besluit van 16 oktober 2007, houdende vaststelling van het tijdstip van inwerkingtreding van de wet van 24 mei 2007 tot uitvoering van richtlijn nr. 2004/25/EG van het Europees Parlement en de Raad van de Europese Unie van 21 april 2004 betreffende het openbaar overnamebod (Stb. 202).

2 Overweging 2 Overnamerichtlijn.

3 E. Berglöf \& M. Burkart, European takeover regulation, Economic Policy (18) 2003, afl. 36, p. 171-213; K.J. Hopt, Takeover defenses in Europe. A comparative, theoretical and policy analysis, Colombia Journal of European Law (20) 2014, afl. 2, p. 252. 
richtlijn vastgestelde of ingevoerde voorschriften valt. De lidstaten zijn vrij om een toezichthoudende autoriteit aan te wijzen, zonder dat er eisen worden gesteld aan de rechtsvorm of de publiek- of privaatrechtelijke aard van de autoriteit. Belangrijk is dat de aangewezen autoriteit onpartijdig en onafhankelijk dient te zijn in de uitoefening van haar taken. ${ }^{4}$

De Overnamerichtlijn bevat voorts enkele regels met betrekking tot de verschillende taken en bevoegdheden van de toezichthoudende autoriteit. Zo moet de toezichthoudende autoriteit gebonden zijn aan het beroepsgeheim en dient deze, wanneer dat voor de toepassing van de in de richtlijn vastgestelde voorschriften noodzakelijk is, gegevens te delen met toezichthoudende autoriteiten van andere lidstaten. ${ }^{5}$ Daarnaast moet de toezichthoudende autoriteit kunnen beschikken over alle bevoegdheden die voor de uitoefening van haar taken nodig zijn en moet zij er zorg voor dragen dat de biedingsvoorschriften worden nageleefd. ${ }^{6}$ De lidstaten dienen er eveneens zorg voor te dragen dat de toezichthoudende autoriteit te allen tijde alle nodige inlichtingen voor de uitoefening van haar taken ontvangt van partijen bij een bod, waar dat wordt verzocht. ${ }^{7}$

Naast deze regels geeft de Overnamerichtlijn de lidstaten enkele specifieke opties voor het toezicht. Zo moet de toezichthoudende autoriteit de mogelijkheid hebben om in bepaalde omstandigheden een uitzondering of afwijking van de regels te bieden. ${ }^{8}$ De lidstaat kan de toezichthoudende autoriteit machtigen om op grond van duidelijk omschreven criteria de billijke prijs te wijzigen. ${ }^{9}$ Daarnaast biedt de richtlijn de toezichthoudende autoriteit de mogelijkheid om het bod goed te keuren en de termijn voor de aanvaarding van het bod te wijzigen. ${ }^{10}$ In art. 17 van de Overnamerichtlijn wordt de lidstaten opgedragen sancties op te stellen voor overtredingen van de ter uitvoering van de Overnamerichtlijn vastgestelde nationale bepalingen. Deze sancties dienen doeltreffend, evenredig en afschrikkend te zijn en de lidstaten dienen alle maatregelen te treffen die nodig zijn om de oplegging van de sancties te verzekeren.

\subsection{Toezicht en handhaving bij het verplicht bod: huidige Nederlandse regeling}

In Nederland zijn twee instanties aangewezen aangaande de regeling van het verplicht openbaar bod. Dit zijn de Autoriteit Financiële Markten (AFM) en de Ondernemingskamer. ${ }^{11}$ De AFM is door de wetgever verkozen om toezicht te houden op de procedure van een openbaar bod. ${ }^{12}$ Het toezicht houden op het uitbrengen en het naleven van een verplicht bod is evenwel niet bij de AFM neerge-

4 Art. 4 lid 1 Overnamerichtlijn.

5 Art. 4 lid 3 en 4 Overnamerichtlijn.

6 Art. 4 lid 5 Overnamerichtlijn.

7 Art. 6 lid 5 Overnamerichtlijn.

8 Overweging 6 Overnamerichtlijn.

9 Art. 5 lid 4 Overnamerichtlijn.

10 Art. 6 lid 2 en art. 7 lid 2 Overnamerichtlijn.

11 Zie ook AFM, 10 jaar AFM toezicht op openbare biedingen, 2011.

12 Kamerstukken I 2006/07, 30419, C, p. 6. 
legd maar bij de Ondernemingskamer. ${ }^{13}$ Handhaving geschiedt door maatregelen van de Ondernemingskamer als gevolg van een verzoek van een verzoekende partij op basis van art. 5:70 van de Wet op het financieel toezicht (Wft). De keuze voor de Ondernemingskamer heeft de wetgever met drie argumenten onderbouwd. Ten eerste beschikt de Ondernemingskamer over specifieke kennis met betrekking tot openbare biedingen, aangezien zij ook besluit over de beschermingsconstructies en het uitkoop- en uittreedrecht. ${ }^{14}$ Het tweede argument is dat de personen die het meest in hun belang getroffen zijn in rechte moeten kunnen optreden zonder gebonden te zijn aan of afhankelijk te zijn van een toezichthouder. ${ }^{15}$ Ten slotte biedt de Ondernemingskamer de mogelijkheid om civielrechtelijke maatregelen te treffen. Dit werd als een voordeel gezien, omdat dit in de regel effectiever is dan bestuursrechtelijke handhaving. ${ }^{16}$ Dergelijke handhaving is volgens de wetgever met name effectief indien er sprake is van 'calculerende partijen', een partij die het voordeel van niet-naleving afweegt tegen het nadeel van de opgelegde sanctie. ${ }^{17}$

De Ondernemingskamer is aldus onder meer bevoegd, na een gedaan verzoek, tot het bevelen om een bod uit te brengen op grond van art. 5:73 lid $1 \mathrm{Wft}$. Het toezicht op het ontstaan van de biedplicht is door de wetgever daarmee dus eigenlijk niet aan een instantie toegekend, maar overgelaten aan de markt. ${ }^{18}$ In Nederland ontbreekt derhalve actief toezicht op het ontstaan van de biedplicht. Als rechterlijke instantie kan de Ondernemingskamer immers slechts een afwachtende houding aannemen met betrekking tot de handhaving van de biedplicht. ${ }^{19}$ Civielrechtelijke sancties kunnen alleen op verzoek van de personen in art. 5:73 lid $1 \mathrm{Wft}$ worden ingesteld. Dit was een bewuste keuze van de wetgever. Volgens de wetgever zijn de betrokken doelvennootschap en aandeelhouders, die het dichtst bij de vennootschap staan, beter in staat om een verplicht-bodsituatie te herkennen dan een actieve toezichthouder. ${ }^{20}$ Daarnaast wordt er waarde gehecht aan het feit dat de partijen die benadeeld worden door niet-naleving van de biedplicht zelf in rechte kunnen optreden. ${ }^{21}$ De betrokken partijen hebben immers de mogelijkheid om bij een verplicht-bodsituatie een verzoekschrift in te dienen bij de Ondernemingskamer. ${ }^{22}$

Door het toezicht bij de markt te leggen wordt de eigen verantwoordelijkheid van de betrokken partijen benadrukt. Aangezien de betrokken partijen het meeste

Kamerstukken II 2005/06, 30419, 3, p. 4 en 5.

Kamerstukken II 2005/06, 30419, 3, p. 6; art. 2:359c en 2:359d BW.

Kamerstukken II 2005/06, 30419, 3, p. 6.

Zie J.H.L. Beckers, De acting in concert regeling inzake het verplicht bod op effecten, Deventer: Wolters Kluwer 2016, p. 495.

Kamerstukken II 2005/06, 30419, 3, p. 6.

Kamerstukken II 2005/06, 30419, 4, p. 12.

Zo ook C.M. Grundmann-van de Krol, Koersen door de Wet op het financieel toezicht, Den Haag: Boom Juridische uitgevers 2012, p. 482-485.

Kamerstukken II 2005/06, 30419, 3, p. 6.

Kamerstukken II 2005/06, 30419, 3, p. 6.

Kamerstukken II 2005/06, 30419, 4, p. 12. 
belang hebben bij de naleving van de biedplicht, was de gedachte van de wetgever dat zij gebruik zouden maken van hun bevoegdheden. ${ }^{23}$ De mogelijkheid om naast de betrokken partijen ook een toezichthoudende instantie een actieve rol te geven bij het toezicht op de naleving van de biedplicht is voorts achterwege gelaten om het risico op het free-rider-probleem zo klein mogelijk te houden. ${ }^{24}$ Het free-rider-probleem is volgens de wetgever de omstandigheid dat betrokken partijen niet van hun bevoegdheden gebruik maken, maar verwachten dat de toezichthouder dit wel zal doen. ${ }^{25}$ Gelet op het feit dat een actieve toezichthouder volgens de wetgever daarom geen toegevoegde waarde heeft, maar wel leidt tot extra kosten die uit algemene middelen en bijdragen van de sector bekostigd zouden moeten worden, is ervan afgezien om een actieve toezichthouder aan te wijzen. ${ }^{26}$

Ons inziens is de huidige situatie strijdig met de strekking van de richtlijn. ${ }^{27}$ Immers, de minderheidsaandeelhouder geniet onvoldoende bescherming indien er geen actief toezicht op het ontstaan van de biedplicht bestaat. Het ontbreken van een actieve toezichthouder betekent ook dat er geen toezichthouder is die inlichtingen kan vorderen van betrokken partijen en andere (internationale) toezichthouders van informatie kan voorzien. ${ }^{28}$ Ook zijn wij er niet van overtuigd dat de betrokken partijen een betere inschatting van de situatie kunnen maken en daarmee bijvoorbeeld ook kunnen beoordelen of er sprake is van acting in concert. ${ }^{29}$ Aandeelhouders zullen ons inziens zeker niet altijd noodzakelijk goed kunnen inschatten of sprake is van acting in concert. Bovendien zal ook tussen de aandeelhouders het free-rider-probleem kunnen spelen, wanneer aandeelhouders verwachten of hopen dat een andere aandeelhouder het wel oppakt. ${ }^{30}$ De wetgever heeft dit risico bij de implementatie van de Overnamerichtlijn ook erkend. Indien er in de praktijk na enkele jaren zou blijken dat de belanghebbenden onvoldoende in staat zijn geweest om acting in concert aannemelijk te maken, zou de wetgever een wijziging in het stelsel van toezicht overwegen. ${ }^{31}$ In 2015 heeft deze evaluatie plaatsgevonden. ${ }^{32}$ Hoewel de minister in de evaluatie erkent dat de betrokken partijen niet altijd zicht hebben op de vraag of er sprake is van acting in concert, was dat geen aanleiding voor een wijziging in het toezichtsysteem. ${ }^{33}$ Het effect van de gekozen vormgeving is ondertussen overduidelijk. Sinds de inwer-

Kamerstukken II 2005/06, 30419, 3, p. 6.

Kamerstukken II 2005/06, 30419, 3, p. 6.

Kamerstukken II 2005/06, 30419, 3, p. 6.

Kamerstukken II 2005/06, 30419, 8, p. 6.

Zo ook: C.J.C. de Brauw, Overnames van beursvennootschappen (Serie Onderneming en Recht, deel 143), Deventer: Wolters Kluwer 2017, p. 860-862; Beckers 2016, p. 485.

Overweging 15 Overnamerichtlijn.

Kamerstukken II 2005/06, 30419, 3, p. 6.

Zo ook: Beckers 2016, p. 488.

Kamerstukken II 2005/06, 30419, 8, p. 20.

Kamerstukken II 2015/16, 32545, 43.

Kamerstukken II 2015/16, 32545, 43, p. 6. 
kingtreding van de Overnamerichtlijn heeft nog geen enkele nalevingsactie op grond van art. 5:73 lid $1 \mathrm{Wft}$ plaatsgevonden. ${ }^{34}$

Het toezicht op het vaststellen van een billijke prijs van art. 5:80a Wft is eveneens aan de Ondernemingskamer toebedeeld. ${ }^{35}$ Dit onder meer omdat de Ondernemingskamer reeds ervaring had met vennootschappelijke procedures, en in het bijzonder met de uitkoopprocedure. ${ }^{36}$ Daarnaast kreeg de Ondernemingskamer de voorkeur boven de AFM voor het toezicht op de billijke-prijsregels, omdat de rol van de AFM voornamelijk procedureel van aard is. ${ }^{37}$ Een derde reden die genoemd is, is het feit dat dit aansloot bij de keuze om de handhaving ook bij de Ondernemingskamer neer te leggen. ${ }^{38}$ Ons inziens lijkt evenwel ook deze invulling strijdig met de strekking van de richtlijn. Immers, de Ondernemingskamer kan de vastgestelde billijke prijs slechts wijzigen op verzoek en niet uit eigen beweging. ${ }^{39}$

\section{Toezicht en handhaving bij het verplicht bod in rechtsvergelijkend perspectief}

\subsection{Toezicht en handhaving bij het verplicht bod in België}

In België is de Autoriteit voor Financiële Diensten en Markten (FSMA) belast met het toezicht op de naleving van de biedplicht. ${ }^{40}$ De FSMA is een autonome publieke autoriteit, ofwel een bij wet opgerichte autoriteit die zaken van nationaal belang, die haar bij wet zijn toegewezen, onafhankelijk uitvoert. ${ }^{41}$ Het toezicht op de biedplicht ligt exclusief bij de FSMA, er zijn geen andere instanties aangewezen. Naast de algemene bevoegdheden heeft de FSMA in art. 35 tot en met 40 van de Belgische Overnamewet verschillende verstrekkende bevoegdheden toegekend gekregen. Hieronder vallen de inlichtingenvordering, de mogelijkheid tot schorsing van een bod, de publicatie daarvan en de verplichting tot het uitbrengen van het bod. De Belgische wetgever zag deze bevoegdheden als noodzakelijk om naleving van het verplicht bod te kunnen handhaven. ${ }^{42}$ Door de inlichtingenbevoegdheid heeft de FSMA de mogelijkheid om inhoudelijke afspraken tussen biedende partijen boven tafel te krijgen. Deze informatie zou voor aandeelhouders of de doelvennootschap veelal moeilijk te verkrijgen zijn. Daarnaast kan de FSMA bij niet-naleving van de verplicht-bodregeling de verantwoordelijke partij verbieden om gebruik te maken van de rechten en voordelen die uit de transactie voortkomen. ${ }^{43}$ Indien het verplicht bod niet wordt nageleefd, kan de FSMA de

Zie ook De Brauw 2017, p. 861.

Kamerstukken I 2006/07, 30419, C, p. 6.

Kamerstukken I 2006/07, 30419, C, p. 6.

Kamerstukken I 2006/07, 30419, C, p. 6.

Kamerstukken I 2006/07, 30419, C, p. 6.

Zo ook: Beckers 2016, p. 493; Grundmann-van de Krol 2012, p. 477.

Art. 35 Overnamewet.

FSMA, Annual report of the FSMA, 2018, p. 5.

J.H.L. Beckers, Acting in concert-primeur in België, Ondernemingsrecht 2010/57, p. 286-292.

Art. 36-39 Overnamewet. 
persoon die nalaat een verplicht bod uit te brengen, hoewel hij daar volgens de wet toe verplicht is, bevelen om alle noodzakelijke maatregelen te treffen. ${ }^{44}$ Indien een persoon niet voldoet aan een bevel of verbod van de FSMA kan zij een last onder dwangsom opleggen. ${ }^{45}$ Daarnaast heeft de FSMA de mogelijkheid om een boete op te leggen indien de maatregelen niet worden nageleefd. ${ }^{46}$

\subsection{Toezicht en handhaving bij het verplicht bod in Duitsland}

De toezichthoudende autoriteit betreffende de biedplicht in Duitsland is de Bundesanstalt für Finanzdienstleitungsaufsicht (BaFin) ${ }^{47}$ Deze autoriteit handelt in het algemeen belang, dus met het oog op het beschermen van de kapitaalmarkt en het investerende publiek in het algemeen, in plaats van dat zij opkomt voor individuele belangen van aandeelhouders. ${ }^{48}$ De BaFin beschikt over dwangmiddelen en heeft een verregaande inlichtingenbevoegdheid. ${ }^{49} \mathrm{Zij}$ kan van eenieder, dus niet slechts belanghebbenden, documenten vorderen en zij kan voorts personen ondervragen. ${ }^{50}$ De BaFin heeft ook de mogelijkheid om op schriftelijk verzoek van de biedende partij(en) deze te ontheffen van de biedplicht indien er voldoende rekening is gehouden met de te behartigen belangen. ${ }^{51}$ Indien een partij niet voldoet aan de biedplicht en zij geen ontheffing heeft, wordt het stemrecht van de biedende partij geschorst. ${ }^{52}$ Tegen een besluit van de BaFin staat hoger beroep open bij de bestuursrechter. ${ }^{53}$

\subsection{Toezicht en handhaving bij het verplicht bod in Frankrijk}

De Franse toezichthoudende autoriteit is de Autorité des Marchés Financiers (AMF). De AMF is een administratieve en onafhankelijke autoriteit. De AMF bestaat uit le Collège, waarin zestien leden plaatsnemen, en la Commission des Sanctions met twaalf leden. Le Collège is het besluitvormende orgaan en is verantwoordelijk voor nieuwe verordeningen en initieert de sanctieprocedure. La Commission des Sanctions is verantwoordelijk voor de uitoefening van de sancties en heeft volledige beslissingsautonomie. ${ }^{54}$ De secretaris-generaal heeft de verantwoordelijkheid over de verschillende afdelingen van de AMF en neemt het besluit tot het openen van een onderzoek of controle, indien hij vermoedt dat er niet wordt voldaan aan de wettelijke vereisten. ${ }^{55}$

De AMF kent het Règlement Général. In dit reglement staan bepalingen opgenomen over het overnameproces en het verplicht bod. Indien er onduidelijkheid 
bestaat over het reglement, kunnen partijen de AMF consulteren over de toelaatbaarheid van een beoogde transactie. De Franse wetgever heeft de AMF toegerust met verschillende handhavings- en sanctiebevoegdheden. Le Collège bepaalt aan de hand van het rapport van de secretaris-generaal of er een sanctieprocedure in gang wordt gezet door la Commission des Sanctions. In geval van niet-nakoming van de biedplicht, of een andere schending van wettelijke bepalingen die aandeelhouders beogen te beschermen, kan la Commission des Sanctions een boete of een administratieve sanctie opleggen. ${ }^{56}$ Bovendien wordt het stemrecht van de aandelen van de biedende partij, die de 30-procentdrempel overschrijden, opgeschort. ${ }^{57}$ In Frankrijk kan beroep tegen besluiten van de AMF worden aangetekend bij de Cour d'appel Paris. ${ }^{58}$

\subsection{Toezicht en handhaving bij het verplicht bod in het Verenigd Koninkrijk}

The Takeover Panel is in het Verenigd Koninkrijk aangemerkt als de toezichthoudende autoriteit. The Takeover Panel is een onafhankelijke entiteit met maximaal 36 leden met expertise in overnames, de effectenmarkt, industrie en handel. ${ }^{59}$ De belangrijkste taak van The Takeover Panel is het waarborgen van de regels uit The Takeover Code. Dit probeert hij zo veel mogelijk te bewerkstelligen door een consensuele aanpak met de betrokken partijen. De focus ligt op snelheid en het vinden van de juiste remedie of sanctie voor de geschonden regel. Een schending van The Takeover Code wordt aangemerkt als een schending van het vertrouwen in de markt. De sancties die The Takeover Panel oplegt, hebben onder meer als gevolg dat de partij die in strijd met een regel heeft gehandeld, lastiger een goede advocaat of zakenpartner zal kunnen vinden.

The Takeover Panel is bevoegd om rulings op te stellen over de interpretatie, effecten of toepassing van de relevante regels. ${ }^{60} \mathrm{Zo}$ heeft The Takeover Panel meerdere keren verduidelijking gegeven over de acting in concert-regels. ${ }^{61}$ Met een ruling kan The Takeover Panel uitspraken doen die bijvoorbeeld inbreuken op The Takeover Code beperken of betaling van een vergoeding aan aandeelhouders vereisen. ${ }^{62}$ Daarnaast is hij bevoegd tot het vorderen van informatie, het opleggen van sancties, en tot slot om een rechterlijke uitspraak te vragen. In het Verenigd Koninkrijk is het verplicht om The Takeover Panel te consulteren indien er twijfels bestaan over de geldende regels met betrekking tot een voorgenomen transactie. ${ }^{63}$ The Takeover Panel verduidelijkt bij een dergelijke consultatie de toepasselijke regels, zodat de voorgenomen transactie in overeenstemming met de relevante regels uitgevoerd kan worden. ${ }^{64}$ Indien The Takeover Panel van

61 The Takeover Panel, Annual report of The Takeover Panel, 2015; The Takeover Panel, Annual report of The Takeover Panel, 2016.

62 Section 946 en 954 Companies Act.

63 The Takeover Code, Introduction sub $6 \mathrm{~b}$.

64 The Takeover Code, Introduction sub 6b. 
mening is dat een partij niet in overeenstemming met The Takeover Code handelt, legt de Executive, indien een partij daarmee instemt, autonoom disciplinaire maatregelen op. ${ }^{65}$ Als een partij niet instemt, kan de Hearings Committee sancties opleggen. ${ }^{66}$ Tegen een besluit van de Hearings Committee staat beroep open bij The Takeover Appeal Board. ${ }^{67}$ In de praktijk wordt er zelden gebruik gemaakt van de beroepsmogelijkheden. De Executive doet veel uitspraken over verschillende soorten zaken, waaronder uitspraken over de precieze omvang van openbaarmakingsverplichtingen en over het al dan niet moeten uitbrengen van een verplicht bod, maar dit leidt niet vaak tot beroep. ${ }^{68}$

\subsection{Rechtsvergelijkende synthese}

In elk van de vier onderzochte landen is, anders dan in Nederland, een autoriteit aangewezen die actief ziet op het toezicht en de handhaving van het verplicht bod. De toezichthouder dient beschikking te hebben over de relevante informatie om de biedplicht vast te stellen. In Nederland ligt de verantwoordelijkheid voor deze informatievoorziening bij de belanghebbenden van de onderneming. Dit kan tot een bewijsprobleem leiden, waardoor handhaving van het verplicht bod in Nederland alsdan wordt bemoeilijkt. De onderzochte autoriteiten uit de vier lidstaten hebben alle een inlichtingenbevoegdheid en een eigen mogelijkheid tot het doen van onderzoek die niet afhankelijk is van een verzoek van belanghebbenden. Dit gebeurt in de praktijk ook regelmatig. De onderzochte buitenlandse toezichthoudende autoriteiten kunnen voorts, eveneens anders dan in Nederland, guidance over hun handhavingsbeleid aan marktpartijen verstrekken en ze zijn eenvoudig benaderbaar. Ook kan in elk van de onderzochte rechtsstelsels de toezichthoudende autoriteit handhavend optreden. Dit zal bijdragen aan de rechtszekerheid en een efficiëntere overnamemarkt.

\section{Herziening van het toezicht op en de handhaving van de verplicht- bodregeling in Nederland}

\subsection{Algemeen}

In paragraaf 2 hebben wij geconcludeerd dat de huidige situatie van het toezicht op en handhaving van de verplicht-bodregeling in Nederland strijdig is met (de strekking van) de richtlijn. Daarnaast geldt, mede gelet op de rechtsvergelijking, dat het in de praktijk van belang is dat de toezichthouder actief toezicht kan houden en de mogelijkheid moet hebben om inlichtingen te verkrijgen. De toezichthouder moet voorts voor marktpartijen benaderbaar zijn om toelichting te kunnen geven over de toepasselijkheid van de regels van de biedplicht op een voorgenomen transactie. Daarnaast heeft het toegevoegde waarde als de toezichthouder richtsnoeren aan de markt kan verstrekken. Dit betekent derhalve dat ons

65 The Takeover Code, Introduction sub 11a.

66 The Takeover Code, Introduction sub 11b.

67 The Takeover Code, Introduction sub 8.

68 P. van Hooghten, The European Takeover Directive and its implementation, Oxford: Oxford University Press 2009, p. 753. 
inziens het huidige Nederlandse systeem moet worden herzien. In de volgende paragrafen bespreken wij daartoe een aantal oplossingen.

\subsection{Optie I: de Nederlandse marktmeester}

Een eerste oplossing is het introduceren van een marktmeester in Nederland naar het voorbeeld van The Takeover Panel uit het Verenigd Koninkrijk in plaats van de huidige handhaving door de Ondernemingskamer. De Overnamerichtlijn biedt de mogelijkheid om het toezicht vorm te laten geven door zelfregulerende partijen. ${ }^{69}$ Voordelen van een marktmeester naar het model in het Verenigd Koninkrijk betreffen vooral de snelheid van handelen, flexibiliteit en bereikbaarheid van de marktmeester. Marktpartijen kunnen de marktmeester consulteren over de toepasselijkheid van de biedingsregels bij een voorgenomen transactie. Daarnaast kan een marktmeester guidance aan de markt verschaffen over zijn handhavingsbeleid door beleidsregels op te stellen en beslissingen te publiceren. Deze mogelijkheden zullen de onzekerheid in de markt doen afnemen. Door de marktmeester vergelijkbare bevoegdheden te geven als The Takeover Panel is actief toezicht mogelijk.

Een dergelijke Nederlandse marktmeester kent echter ook nadelen. Daarvan blijkt uit de resultaten van een onderzoek naar het invoeren van een marktmeester in Nederland. ${ }^{70}$ De conclusie daaruit is dat een marktmeester niet goed in het Nederlandse stelsel past. Beslissingen van The Takeover Panel vinden hun grondslag in de maximalisatie van de aandeelhouderswaarde, naar het shareholdermodel. In Nederland geldt evenwel het Rijnlandse stakeholder-model, waar een bredere en complexere belangenafweging geldt, die bovendien meer subjectief van aard is. Beslissingen van een Nederlandse marktmeester kunnen daardoor eerder onderwerp van discussie worden. Het introduceren van een marktmeester in Nederland naar voorbeeld van The Takeover Panel uit het Verenigd Koninkrijk ligt daarom ons inziens terecht minder voor de hand.

\subsection{Optie II: AFM en Ondernemingskamer}

De tweede optie is een vormgeving waarbij de AFM en de Ondernemingskamer gezamenlijk bevoegd zijn. ${ }^{71}$ De AFM heeft dan bestuursrechtelijke bevoegdheden en de Ondernemingskamer is bevoegd tot het civielrechtelijk sanctioneren bij schending van de biedplicht. De AFM kan dan als benaderbare toezichthouder gelden die duidelijkheid kan verschaffen in praktijksituaties. De AFM zou dan tevens de bevoegdheid kunnen krijgen om een vrijstelling of ontheffing te geven in bepaalde situaties, zoals bij acting in concert. Dit is toegestaan volgens de Overnamerichtlijn. ${ }^{72}$ Aangezien de AFM een bestuursorgaan is, moet er een

69 Overweging 7 Overnamerichtlijn en art. 4 lid 1 en 21 lid 1 Overnamerichtlijn.

70 Kamerstukken II 2008/09, 31083, 33.

71 Een dergelijk systeem wordt bepleit door onder meer De Brauw 2016, p. 864-866; M.P. Nieuwe Weme, Het verplicht bod op effecten, Deventer 2004, p. 224-225; L.J. Hijmans van den Bergh \& G. van Solinge, Implementatie van de dertiende richtlijn: een terreinverkenning. Preadvies van de Vereeniging 'Handelsrecht', Deventer: W.E.J. Tjeenk Willink 2000, p. 166-167. 
beroepsmogelijkheid zijn bij de bestuursrechter, in dit geval het College van Beroep voor het bedrijfsleven $(\mathrm{CBb}){ }^{73} \mathrm{Er}$ zijn voordelen verbonden aan dit stelsel ten opzichte van het huidige stelsel. De AFM kan dan gebruik maken van haar bevoegdheden, waaronder de inlichtingenbevoegdheid, om actief toezicht te houden op de naleving van de biedplicht. Daarnaast kan zij de markt informeren over het beleid dat de AFM hanteert met betrekking tot vrijstellingen en ontheffingen. Bovendien zorgen de civielrechtelijke sancties van de Ondernemingskamer voor preventieve werking. Het nadeel van een systeem waarbinnen twee toezichthouders actief zijn, is het risico dat de AFM en de Ondernemingskamer bepaalde regels verschillend interpreteren en tot van elkaar afwijkende conclusies komen.

\subsection{Optie III: AFM}

Een derde optie die wij noemen, is om het toezicht op en de handhaving van de biedplicht exclusief bij de AFM neer te leggen. ${ }^{74}$ Met een toezichthoudende en handhavende autoriteit zal het Nederlandse stelsel meer aansluiten bij de stelsels uit de andere onderzochte lidstaten. De AFM heeft door haar bestuursrechtelijke bevoegdheden de mogelijkheid om actief toezicht te houden op de verplicht-bodregeling en is benaderbaar voor marktpartijen om verduidelijking te verschaffen over voorgenomen transacties. Daarnaast kan zij als toezichthouder én enig handhaver duidelijke richtsnoeren aan de markt verschaffen over haar beleid. Bepleit zou voorts kunnen worden om de AFM ook de bevoegdheid te geven om civielrechtelijke sancties op te leggen. In de literatuur is evenwel verdedigd dat het opleggen van civielrechtelijke sancties door de toezichthouder niet past in de Nederlandse rechtssystematiek. ${ }^{75}$ Dit lijkt ons echter een overkomelijk bezwaar, nu DNB als toezichthouder op grond van de Wft ook al civielrechtelijke sancties kan opleggen. ${ }^{76}$

\subsection{De opties gewogen}

In Nederland wordt niet voldaan aan de doelstellingen van de verplicht-bodregeling uit de Overnamerichtlijn. Dit betekent dat het huidige Nederlandse systeem moet worden herzien. In de vorige paragrafen hebben wij daartoe een drietal oplossingen besproken. In elk van de beschreven opties is een toezichthouder aangewezen die actief toezicht kan houden op de biedplicht. De Nederlandse overnamemarkt zal ons inziens het meest profiteren van een toezichthoudende autoriteit die actief toezicht kan houden en daarnaast ook zelf handhavend kan optreden. Een nadeel van optie I is dat het Rijnlandse stakeholder-model minder geschikt lijkt voor een marktmeester dan het shareholder-model uit het Verenigd Koninkrijk. Ons inziens verdient optie III daarom de voorkeur boven de beide

74 Zie ook M.W. Josephus Jitta, De rol van de AFM en die van de Ondernemingskamer in het wetsvoorstel betreffende het openbaar bod, Ondernemingsrecht 2006/69.

75 Nieuwe Weme 2004, p. 230.

76 Zo ook Beckers 2016, p. 514. 
andere opties, nu deze anders dan bij optie II niet tot conflicterende uitkomsten kan leiden.

\section{Conclusie}

De Europese verplicht-bodregeling is onder meer in het leven geroepen om minderheidsaandeelhouders te beschermen tegen de negatieve gevolgen die met een verandering in zeggenschap in een onderneming gepaard kunnen gaan. In de Overnamerichtlijn zijn enkele bepalingen opgenomen om het toezicht op en de handhaving van de verplicht-bodregeling te garanderen. Zo dienen de lidstaten een autoriteit aan te wijzen die belast is met het toezicht en de handhaving. In Nederland wordt hier ons inziens niet correct aan voldaan. Ook in de praktijk kan dit een nadelig effect hebben. ${ }^{77}$ Dit betekent derhalve dat het huidige Nederlandse systeem moet worden herzien. Om dit op te lossen is een drietal opties besproken en gewogen. Wij bepleiten de optie om de AFM exclusief bevoegd te maken. Door de AFM aan te wijzen als exclusief bevoegde toezichthoudende autoriteit wordt er, zo menen wij, op een zo goed mogelijke wijze recht gedaan aan de vereisten en de strekking van de verplicht-bodregeling uit de Overnamerichtlijn. Dit zal bijdragen aan de rechtszekerheid en een efficiëntere overnamemarkt.

Zo leek er in het kader van de overnamestrijd rondom Akzo Nobel in 2017 op enig moment een zekere schijn dat er sprake was van enig gezamenlijk optrekken van Elliott en PPG. Uit een in de openbaarheid gekomen e-mail blijkt bijv. dat een dag na het Shareholders Request medewerkers van Elliott met elkaar mailen: 'Also Wiktor - you should call ppg and let them know that we have sent the EGM request and that now may be an opportune time for ppg to reach out and try to engage.' Doordat er geen actieve toezichthouder is, was er geen mogelijkheid om hier nader onderzoek naar te verrichten. Eventuele acting in concert-activiteiten wordt kortom geen strobreed in de weg gelegd. Dat is zonder meer onwenselijk. 